\title{
Test Report: Cost Effective Foundation Insulation
}

\author{
J. M. Lacey \\ T. E. Rahl \\ G. A Twitchell \\ R. G. Kobbe
}

June 2003

Idaho National Engineering and Environmental Laboratory Bechtel BWXT Idaho, LLC 
INEEL/EXT-03-00741

\title{
Test Report: Cost Effective Foundation Insulation
}

\author{
INEEL: $\quad$ J. M. Lacy \\ T. E. Rahl \\ MAMTC / WY: $\quad$ G. A. Twitchell \\ Univ. of Wyoming: $\quad$ R. G. Kobbe
}

June 2003

Idaho National Engineering and Environmental Laboratory Building Technologies \& Energy Management Department Idaho Falls, Idaho 83415

Prepared for the University of Wyoming

Control No. 01-257 and the

U. S. Department of Energy

Under DOE Idaho Operations Office

Contract DE-AC07-99ID13727 


\section{ABSTRACT}

A field experiment was conducted to demonstrate and quantify the thermal effectiveness of rigid insulation board when installed on the exterior of a buried concrete foundation wall. A heated, insulated box was constructed along one wall of an existing, unheated building to simulate the living space of a home. The crawl space beneath the living space was divided into two sections. One featured external foundation insulation, while the other side had none.

36 temperature and heat flux sensors were installed at predetermined locations to measure the temperature profile and heat flow out of the living space. The temperature profile through the foundation was then used to calculate the total heat flow out of the foundation for both cases.

This experiment showed that a significant energy savings is available with exterior foundation insulation. Over the course of 3 months, the heat-loss differential between the insulated and non-insulated foundations was 4.95 kilowatthours per lineal foot of foundation wall, for a ratio of 3:1. For a $2200 \mathrm{sq}$. $\mathrm{ft}$ home with a foundation perimeter 200 $\mathrm{ft}$. long, this would amount to a savings of $990 \mathrm{~kW}$-hrs in just 3 months, or $330 \mathrm{~kW}$-hrs per month. Extrapolating to an 8-month heating year, we would expect to save over $2640 \mathrm{~kW}$-hrs per year for such a home. The savings for a basement foundation, rather than a crawlspace, would be approach twice that amount, nearing $5280 \mathrm{~kW}-\mathrm{hr}$ per year. Because these data were not collected during the coldest months of the year, they are conservative, and greater savings may be expected during colder periods. 


\section{SUMMARY}

While insulation of basement and crawlspace walls is necessary for a warm and energy efficient home, the common practice of insulating the inside face of the foundation wall can lead to serious moisture-related problems [1]. The fundamental cause of these troubles is that they create a cool concrete foundation surface exposed to warm moist room air on one side, and cool moist soil on the other. Thus moisture from the room air tends to condensate on the concrete surface. If a moisture barrier is placed anywhere in the wall to prevent room air from reaching the concrete, then any moisture that may get into the wall has no path to dry to, and is trapped.

A solution to this dilemma, as detailed in the EEBA Builder's Guide [2], is to place insulation on the outside of the foundation wall, rather than the inside. This solution keeps the foundation wall warm, preventing condensation and leaving the inner surface free to dry to the inside. Because this is a relatively new building technique, and the construction industry is conservative, the efficacy of the approach must be quantitatively determined before it will see widespread acceptance.

The goal of this study, sponsored by the State of Wyoming's Energy Programs Office, was to quantify the reduction in heat loss through the foundation by rigid insulation board placed on the outside of the foundation. This information may then be used to demonstrate the efficacy of external foundation insulation systems in regions where foundation moisture is a serious concern.

A heated, insulated box was constructed along one wall of an existing, unheated building to simulate the living space of a home. The crawl space beneath the living space was divided into two sections. One featured external foundation insulation installed as recommended by the EEBA Builder's Guide (Ref. 1). The other side had none.

36 temperature and heat flux sensors were installed at predetermined locations to measure the temperature profile and heat flow out of the living space. The temperature profile through the foundation was then used to calculate the total heat flow out of the foundation for both cases.

This simple experiment has shown that a significant energy savings is available by insulating the outside of foundations with 2-inch (R 10) rigid insulation board. After 3 months, the heat-loss differential between the two sides was 4.95 kilowatt-hours per lineal foot of foundation wall, for a ratio of 3:1. For a $2200 \mathrm{sq} . \mathrm{ft}$ home with a foundation perimeter $200 \mathrm{ft}$. long, this would amount to a savings of $990 \mathrm{~kW}$-hrs over just 3 months, or $330 \mathrm{~kW}$-hrs per month. Extrapolating to an 8-month heating year, we would expect to save over $2640 \mathrm{~kW}$-hrs per year for such a home. The savings for a basement foundation, rather than a crawlspace, would be approach twice that amount, nearing $5280 \mathrm{~kW}$-hr per year. Because these data were not collected during the coldest months of the year, they are conservative, and greater savings may be expected during colder periods.

While this study demonstrates the thermal effectiveness of external insulation, the characterization of its utility in moist climates will not be complete until its moisture transport properties have been evaluated, especially with respect to internal foundation insulation. It would be quite instructive to build upon the current experimental setup and add internal foundation insulation to the currently uninsulated crawlspace, along with moisture sensors throughout the system. We could then place a measured quantity of water on either side of the foundation wall at will, and monitor the transport and collection of moisture through both systems over the course of a year. 


\section{ACKNOWLEDGEMENTS}

The authors would like to acknowledge their indebtedness to W. D. Richins, T. K. Larson, J. E. Blakely, and A. L. Crawford, of the INEEL Severe Weather Test Site, for their invaluable support at all phases of this project. We would also like to thank Simpson Strong-Tie Company, Inc., whose generous donation of the test building made this effort possible. 


\section{CONTENTS}

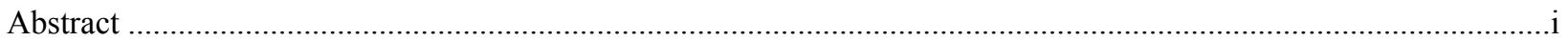

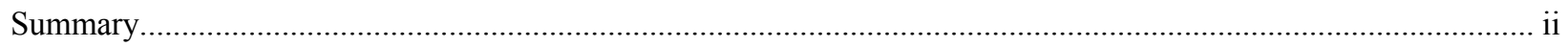

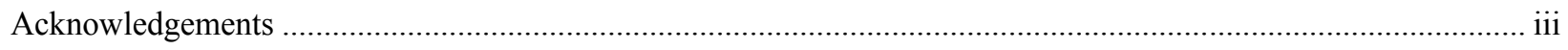

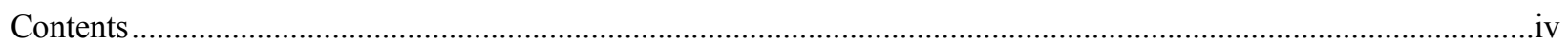

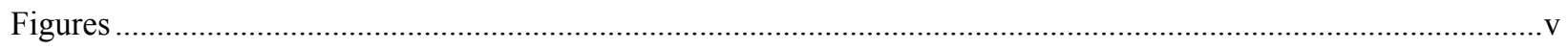

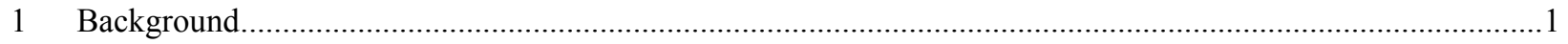

2 Purpose …

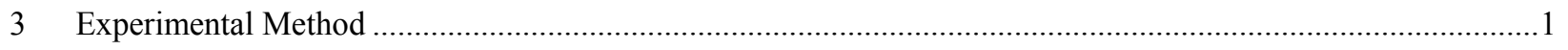

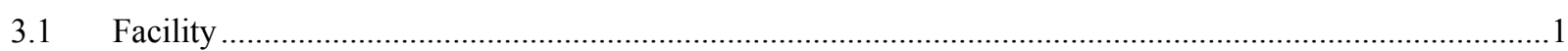

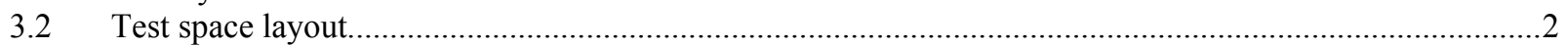

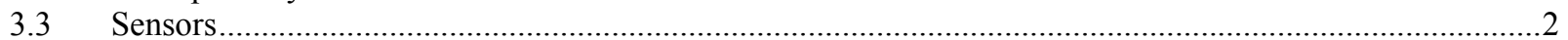

4 Calculation of Energy Flow Through the Foundation .............................................................................

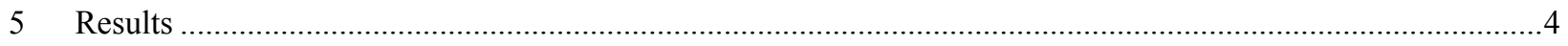

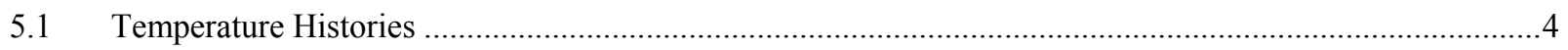

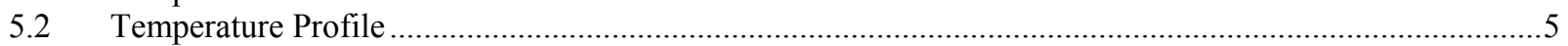

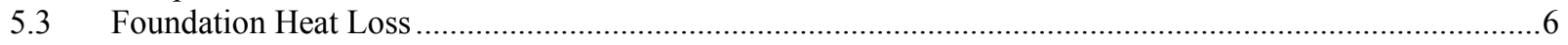

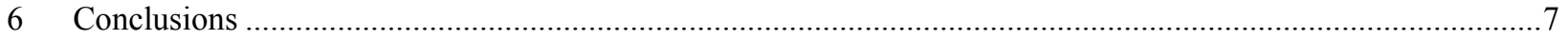

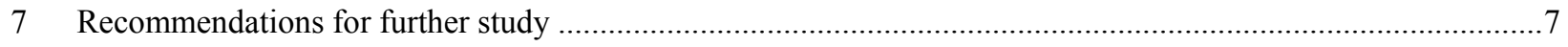

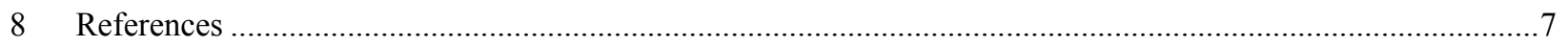

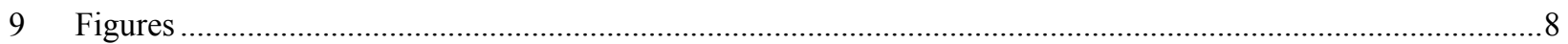




\section{FIGURES}

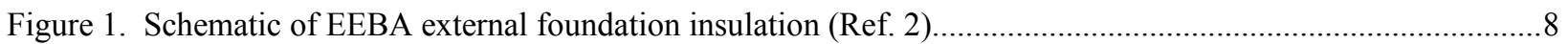

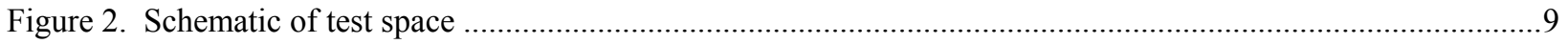

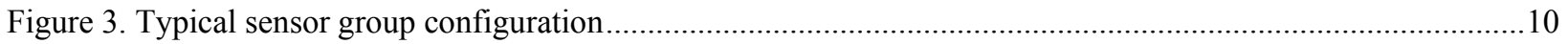

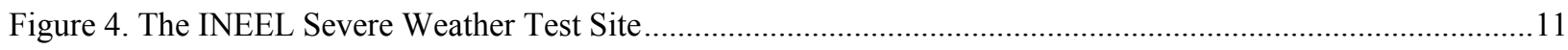

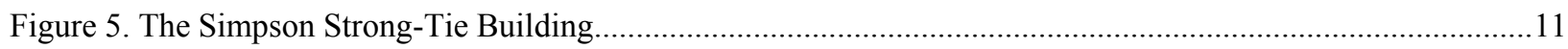

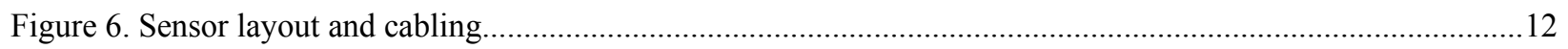

Figure 7. Temperature sensor and heat flux sensor as placed on foundation interior ..............................................12

Figure 8. Temperature sensors installed on outside surface of foundation..............................................................13

Figure 9. Temperature sensors installed on outside face of insulation. ................................................................13

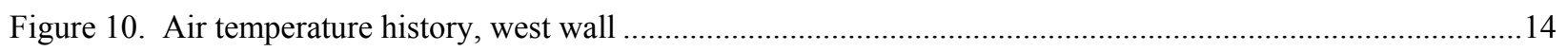

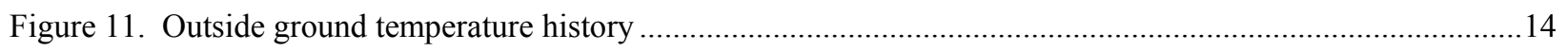

Figure 12. Temperature history of the foundation interior surface ...................................................................15

Figure 13. Temperature history of the foundation exterior surface ……...........................................................15

Figure 14. Crawlspace soil temperature history at 18in. depth...............................................................................16

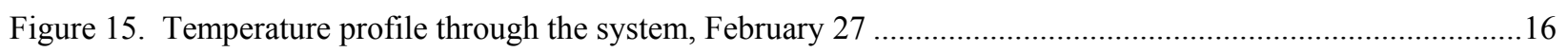

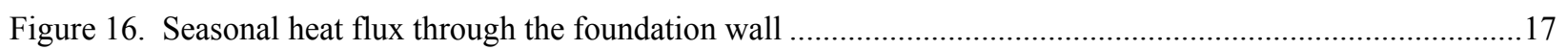

Figure 17. Cumulative energy flow through foundation, per square foot of foundation surface...............................17 


\section{Background}

While insulation of basement and crawlspace walls is necessary for a warm and energy efficient home, the common practice of insulating the inside face of the foundation wall can lead to serious moisture-related problems [1]. Issues can range from a damp, moldy smell, to decay of wood structural members in the basement wall. The fundamental cause of these troubles is that they create a cool concrete foundation surface exposed to warm moist room air on one side, and cool moist soil on the other. Thus moisture from the room air tends to condensate on the concrete surface. If a moisture barrier is placed anywhere in the wall to prevent room air from reaching the concrete, then any moisture that may get into the wall has no path to dry to, and is trapped.

A solution to this dilemma, as detailed in the EEBA Builder's Guide [2], is to place insulation on the outside of the foundation wall, rather than the inside as shown in Figure 1. This solution keeps the foundation wall warm, preventing condensation and leaving the inner surface free to dry to the inside. Because this is a relatively new building technique, and the construction industry is conservative, the efficacy of the approach must be determined before it will see widespread acceptance.

\section{Purpose}

The goal of this study, sponsored by the State of Wyoming's Energy Programs Office, was to quantify the reduction in heat loss through the foundation by insulation board placed on the outside of the foundation. This information may then be used to demonstrate the efficacy of external foundation insulation systems in regions where foundation moisture is a serious concern.

\section{Experimental Method}

A heated, insulated box was constructed along one wall of an existing, unheated building to simulate the living space of a home. The "living space" dimensions are approximately $24 \mathrm{ft}$. long, by $12 \mathrm{ft}$. wide, by $4 \mathrm{ft}$. tall. The low height reduced construction and heating costs, while having no effect on the measurements of interest.

The crawl space beneath the living space was divided into two sections approximately 12 feet square. One featured external foundation insulation installed as recommended by the EEBA Builder's Guide [2]. The other side had no foundation insulation. The divider between the two sides was insulated to prevent thermal communication between them. The ceiling and walls of the living space/ crawl space unit were insulated to minimize heat loss and maintain a relatively constant temperature of $295 \mathrm{~K}\left(72^{\circ} \mathrm{F}\right)$ within the living space. This configuration is illustrated in Figure 2.

36 temperature and heat flux sensors were installed at predetermined locations to measure the temperature profile and heat flow out of the living space. A cross-section of a typical sensor group is shown in Figure 3. Detailed temperature and heat flux data in the crawlspace and through the foundation provided information necessary to directly compare the heat flow between the insulated and uninsulated sides. These energy loss differences were then extrapolated to the foundation of an average full-size home to predict the energy savings associated with the exterior foundation insulation.

\subsection{Facility}

The experiment was conducted at the INEEL's Severe Weather Test Site, near Arlington, Wyoming in the Simpson Strong-Tie Building. This building is an uninsulated, unheated wood structure $24 \mathrm{ft}$ wide by $24 \mathrm{ft}$. deep. The building rests on a $2.5 \mathrm{ft}$. deep foundation, with a gravel floor. Figures 4 and 5 show photographs of the site and test building. 


\subsection{Test space layout}

Figure 2 shows the concept of the test layout, which is divided into 6 thermal spaces as follows:

Area 1. Crawl space, insulated, unheated

Area 2. Crawl space, uninsulated, unheated

Area 3. Living space, insulated, heated

Area 4. Simpson Strong-Tie building balance, uninsulated, unheated

Area 5. Outside air

Area 6. Outside soil

Heat flows from Area 3, the heated living space, through parallel paths through the other enclosed spaces, to the sinks of the outside air and soil. The outside air and soil are considered separate sinks since the air temperature experiences large magnitude daily variations, while the soil temperature is somewhat stable. Sensors were placed along each heat flow path from Area 3 to Areas 5 and 6 in an attempt to monitor the overall heat balance.

Three distinct thermal conditions were measured over the course of the experiment. First, the system was monitored with no heat input into the system. This provided a baseline to which the other cases may be compared, and allowed for compensation of the temperature sensors, if necessary. Second, the living space was heated to a constant $22{ }^{\circ} \mathrm{C}$ $\left(72{ }^{\circ} \mathrm{F}\right)$ with 6 inch batt insulation in the floor between the living space and crawl space. Finally, the floor insulation was removed, providing a relatively high conductivity path from the living space to the crawl space.

\subsection{Sensors}

The sensor suite included 34 temperature transducers and 2 heat flux sensors to monitor the heat flow and temperature gradients in and around the test space, with detailed measurement through the foundation and into the surrounding soil.

Sensors were located in the test structure as illustrated in Figure 6. This sensor layout was developed to

- Reduce or remove uncontrolled variables. Given the orientation of the test space in the building, a layout was chosen to minimize the variability of solar heating, wind, and snow accumulation on the different sensor lines. Minimizing the difference of these effects between the sensor lines increased the chance for a direct comparison of insulated and uninsulated foundation wall properties.

- Reduce susceptibility to single-point failures. Because the experiment spanned a complete winter, the likelihood of failure of individual sensors was an issue for consideration. Given the location of the test site, failed sensors could not have been repaired once winter set in. The layout employed provided some redundancy in the case of one or more sensor failures.

- Measure 2-dimensional cross-flow effects. A single sensor line perpendicular to the surface of interest assumes, by default, the surface to be infinite, with no component of heat flow orthogonal to the sensor line. With multiple parallel lines of sensors, cross flow, such as that caused by solar heating, could be identified if it were an issue.

- Measure heat flow through all paths. Sensors were placed such that heat flow through the ceiling, walls, and earth may be accounted for in the total energy balance of the test space, if desired. Multiple sensors along the path through the insulation provided detail about the temperature and thermal conductivity of every element along the path.

In addition to the sensors installed in the Simpson Strong-Tie building, the experiment had access to a full suite of local meteorological data (wind, temperature, barometric pressure) being gathered continuously at the site by a companion project. 


\subsubsection{Temperature Transducers}

To measure temperatures, 34 Analog Devices AD590K integrated circuit temperature transducers are employed. The sensor properties are shown in Table 1. The output current of each temperature sensor was shunted by a Caddock MK132 $10 \mathrm{~K} \Omega$ resistor (1\% precision), providing a range of approximately $400 \mathrm{mV}$ to the data acquisition system. Individual sensor circuits were calibrated at two temperature points, nominally $273 \mathrm{~K}$ and $300 \mathrm{~K}$, to compensate for variances in both the sensors and resistors. This calibration scheme resulted in an accuracy of within $0.5 \mathrm{~K}\left(0.9^{\circ} \mathrm{F}\right)$ with respect to one another. Because this experiment was concerned with heat flow and differential temperature, the absolute temperature error, expected to be less than $\pm 0.8 \mathrm{~K}\left(1.4^{\circ} \mathrm{F}\right)$, is of less concern.

Sensors were solder connected to 24-gauge twisted-pair copper wire with foil shielding around each pair, and potted in high-conductivity epoxy cement. The potting prevented shorting of the sensor circuit in the presence of moisture. All sensor cables were then routed along the local isotherm for at least 6 inches to minimize heat conduction errors along the wires. The bundled conductors were then routed through underground PVC conduit to the building housing the data acquisition system. All power and AC source conductors were routed in separate conduit well removed from the data conduit to minimize the inductance of noise onto the sensor signals. Figures $6-9$ show examples of how the sensors were installed on the building.

Table 1. AD 590K Temperature Transducer Properties

\begin{tabular}{|l|l|}
\hline Excitation & +4 to $+30 \mathrm{Vdc}$ \\
\hline Output & $298.2 \mu \mathrm{A} @ 25^{\circ} \mathrm{C}$ \\
\hline Sensitivity & $1.0 \mu \mathrm{A} / \mathrm{Kelvin}$ \\
\hline Calibration Error & $\pm 2.5^{\circ} \mathrm{C}$ \\
\hline Absolute Error (w/o calibration adjustment) & $\pm 5.5^{\circ} \mathrm{C}$ \\
\hline Absolute Error (with calibration adjustment) & $\pm 2.0^{\circ} \mathrm{C}$ \\
\hline Repeatability & $\pm 0.1^{\circ} \mathrm{C}$ maximum \\
\hline Long Term Drift & $\pm 0.1^{\circ} \mathrm{C}$ per month maximum \\
\hline
\end{tabular}

\subsubsection{Heat Flux Sensors}

Two Omega Engineering HFS-3 model heat flux sensors were mounted onto the interior face of the foundation wall between adjacent lines of temperature sensors. These units were to provide direct reading of the heat flow through the wall. These units are designed for much higher fluxes than are present in the current experiment, causing their output signal to be quite small. Two Omega Engineering Omni Amp III signal amplifiers, with gain set to x1000, were placed a few inches from the sensors in order to boost the signal strength to usable levels. These signals are transmitted to the data acquisition system as previously described for the temperature sensors.

The published sensitivity of the heat flux sensors is $3^{*} 10^{-6} \mathrm{~V} / \mathrm{btu} / \mathrm{ft}^{2} /$ hour, or $0.110 \mathrm{mV} / \mathrm{Wm}^{2}$. The in-line amplifiers boost the sensitivity to $0.110 \mathrm{~V} / \mathrm{Wm}^{2}$, enough to detect the presence of an outstretched hand over a foot away. Unfortunately, amplified signals from the HFS-3 units proved too noisy to be useful for this experiment, and their data are not included in the results.

\subsubsection{Data Acquisition}

A PC-based system was employed to acquire and store data from the array of sensors along with signals from a concurrent experiment. Signals were routed through terminal blocks into National Instruments SCXI-1102 32channel multiplexing analog input modules mounted in a SCXI-1000 chassis. In combination with the concurrent 
companion experiment, 96 channels were monitored and recorded. System reliability was tested prior to the beginning of the test, and monitored regularly over the course of the winter.

\section{Calculation of Energy Flow Through the Foundation}

Conductive heat flux through a given medium may be given by the equation

$q=\frac{k}{t}\left(T_{1}-T_{2}\right)$ where

$\mathrm{q}$ is the heat flux in watt $/ \mathrm{meter}^{2}$, or in BTU/ft ${ }^{2} \mathrm{hr}$

$t$ is the distance between two points of measurement, 1 and 2 ,

$\mathrm{k}$ is the thermal conductivity of the material, in watt $/ \mathrm{m} * \mathrm{~K}$ or in $\mathrm{BTU} / \mathrm{hr} * \mathrm{ft} *{ }^{\circ} \mathrm{F}$

and $\mathrm{T}_{1}$ and $\mathrm{T}_{2}$ are the temperatures at the two points 1 and 2 .

Then for materials with well-characterized thermal conductivities, such as concrete and Styrofoam insulation, the heat flux may be directly determined from the representative surface temperatures. Total heat flow through a wall is then the heat flux q, times the area of the wall.

Because sensors were installed on both surfaces of the concrete, as well as both surfaces of the insulation and in the soil, it was possible to compare the computed fluxes along each line of sensors to "calibrate" the actual conductivity of the concrete, insulation, and soil.

Enough sensors were placed that it was possible to calculate the energy balance for the entire heated space, although this was determined to be unnecessary. Finally, the difference in heat flux in the insulated and uninsulated foundations may be employed to compute the savings one might expect for an average home over the course of a winter.

\section{Results}

The test space was built and all sensors in place and taking data by mid-December. With a month of baseline unheated data recorded, we traveled to the site and began heating the system on January 20. On February 19, the floor insulation was removed to record the heat flow in the third condition (no insulation between floor and crawl space). Only one temperature sensor failed over the course of the experiment, and that occurred within weeks of initial installation, before heat was applied to the living space. That sensor was replaced without affecting the quality of the subsequent data.

The system was monitored and recorded continuously from December 20, 2002, through May 19, 2003. Of that time, 3 months, from February 16 through May 19, were of the primary thermal condition of interest. During that period, the system was set up to most closely reflect the heat flow through a typical inhabited home. The following sections present data gathered and its interpretation.

\subsection{Temperature Histories}

Figure 10 traces the temperature of the outside air near the west wall of the test building, above the sensor lines on the foundation. The Figure shows daily temperature swings as large as $30^{\circ} \mathrm{C}$. This large cycle amplitude is due to solar heating of the west wall in the late afternoons. High temperatures due to insolation are of short duration, spanning approximately 2 hours from heat up and to cool-down. Therefore the lower edge of the trace more accurately reflects the average air temperature experienced by the soil and foundation wall, though heating of the system in those few hours per day cannot be ignored. Including the effect of solar heating on the wall, the air temperature ranged from a minimum of $-29^{\circ} \mathrm{C}$ on 27 February, to a maximum of $35^{\circ} \mathrm{C}$ on 10 April.

The temperature of the ground was naturally much more stable, as may be seen in Figure 11. This figure shows the temperature of the soil 24 in. below the ground surface and 12 in. away from the foundation, at 5 stations along the 
length of the foundation wall. The ground temperature traces are fairly tightly clustered, and do not show any significant influence from the proximity to either the non-insulated or insulated halves of the foundation. Nor does there appear to be a significant thermal gradient along the length of the wall. This fact allows us to approximate the heat transfer through the foundation system as 1-dimensional in our analysis. The ground temperature reached a minimum of $-1{ }^{\circ} \mathrm{C}$ in mid-February, climbing to $9^{\circ} \mathrm{C}$ by mid-May.

The next two Figures, 12 and 13, trace the temperature of the inner and outer faces of the concrete foundation wall 24 in. below the soil surface. The effect of the insulation is apparent here, especially on the outer foundation face where the insulated side stayed as much as $2^{\circ} \mathrm{C}$ warmer than the non-insulated side. While this may not seem like a large difference, it noticeably affects the heat flow through the wall, as is discussed in the following section.

The final temperature trace, in Figure 14, is of the soil temperature in the crawlspace $18 \mathrm{in}$. below the surface, in each of the two halves. It would be expected that the insulated crawlspace soil would be warmer than the noninsulated side, which is indeed the case for most of the record. However, for a period of approximately a month between 10 March and 10 April, the non-insulated half was the warmer of the two, for reasons not immediately apparent.

\subsection{Temperature Profile}

Figure 15 is a snapshot of the temperatures along the conduction path from the living space to the outside air and soil. The Figure represents the 24-hour mean temperature from 11:00 am February 27 to 11:00 am February 28. Each bar cluster represents a location along the conduction path, with the individual bars the temperature on one of the lines described in Figure 6. Not all lines are represented at every point because lines were not fully instrumented at every location. As an example, only one sensor was employed in each of the two crawlspace areas to measure the temperature below the surface. Thus only two bars display the crawlspace soil temperature. Similarly, as there was no "outside surface of insulation" on the non-insulated side.

The thermal conductivity of concrete spans a range dependent upon the materials and ratios employed, void fraction, and moisture content. Because the thermal properties of rigid foam insulation board are stable and have been fairly thoroughly characterized, we may use the profile information to refine our estimate of the thermal conductivity of the concrete foundation wall. This value will be utilized for our subsequent heat flux analysis. Given a 1dimensional heat flow assumption (validated by the temperature profiles as discussed previously), the flux through the insulated foundation must equal the flux through the insulation, or

$q=\frac{k_{\text {concrete }}}{t_{\text {concrete }}} * \Delta T_{\text {concrete }}=\frac{k_{\text {insulation }}}{t_{\text {insulation }}} * \Delta T_{\text {insulation }}$

rearranging, we solve for the concrete's conductivity

$k_{\text {concrete }}=k_{\text {insulation }} * \frac{t_{\text {concrete }}}{t_{\text {insulation }}} * \frac{\Delta T_{\text {insulation }}}{\Delta T_{\text {concrete }}}$

If we wish to use R-value notation, we note that R-value is simply material thickness divided by conductivity. Substituting the insulation board R-value of 10 , concrete thickness of 8 in. ( $0.67 \mathrm{ft}$.)., and averaged temperature differentials across the concrete and insulation of $.47^{\circ} \mathrm{C}$ and $4.57^{\circ} \mathrm{C}$ respectively (from Figure 15), we find

$k_{\text {concrete }}=\frac{t_{\text {concrete }}(f t)}{R_{\text {insulation }}} * \frac{\Delta T_{\text {insulation }}}{\Delta T_{\text {concrete }}}=0.652 \frac{B T U}{\circ F \cdot F t \cdot H r}$

This corresponds well with the range from 0.54 (dry) to 0.70 (10\% moisture) for concrete published in [3]. 


\subsection{Foundation Heat Loss}

\subsubsection{Flux}

Figure 16 shows the time history of the heat flow through the foundation over the course of the winter. These values were calculated via equation (1), employing the conductivity of the concrete foundation calculated above, with the difference between the temperatures of the inner and outer concrete surfaces. The six data curves represent the six instrumented locations along the foundation wall as shown in Figure 6. Lines 1-3 are on the insulated side and 4-6 are on the non-insulated side. Line numbers range from near the building centerline (lines 1 and 4 ) to near the building corners (lines 3 and 6 ).

Two vertical lines on the heat flux traces demarcate the three thermal conditions we monitored - first, there was no heat in the living space and the floor between the living space and the crawl space was insulated. Heaters were installed and powered up on January $20^{\text {th }}$, leading to the second condition-- with heat and floor insulation. Four weeks later, on February 16, we removed the floor insulation, yielding the thermal condition of most interest for the foundation study. This state most closely reflected the heat flow through a typical home, with the living space heated to $72^{\circ} \mathrm{F}\left(22^{\circ} \mathrm{C}\right)$, without insulation between the first floor and the crawlspace. The three conditions are distinct from one another in the Figure. In phase one, where no heat is added to the system, only a very small heat flux is apparent. This is caused by solar heating of the enclosed building system relative to the exposed ground. After heat was applied to the living space, the gap between the insulated and non-insulated lines increased somewhat, but the presence of the floor insulation kept the flow of heat into the crawlspace, and through the foundation, to a minimum. There is therefore only a minor difference between the flux values for the insulated and non-insulated sides.

When the floor insulation was removed in late February, the difference in heat flux through the two sides became quite distinct. In the 14 days from February $16^{\text {th }}$, when the floor insulation was removed, to March $2^{\text {nd }}$, the heat flow out of the non-insulated foundation wall climbed from $2.5 \mathrm{watt} / \mathrm{m}^{2}$ to $7 \mathrm{watt} / \mathrm{m}^{2}$, while the insulated side climbed from $1 / 2 \mathrm{watt} / \mathrm{m}^{2}$ to as much as $3 \mathrm{watt} / \mathrm{m}^{2}$. The heat flow through line 3 on the insulated side remained nearly constant, rising only to $1.4 \mathrm{watt} / \mathrm{m}^{2}$. Flux through line three remained below that of the others in its group for the remainder of the season. This may be a result of an environmental condition such as a snow drift insulating the ground and reducing the temperature gradient in that location, or a sensor anomaly.

In general, the flux through the non-insulated foundation is approximately 2-1/2 to 3 times of that on the insulated side.

\subsubsection{Cumulative Effects}

While the difference in the instantaneous energy flow rates is clear, it does not relate clearly the overall energy consumption, and thus cost difference, between the insulated and non-insulated sides.

This comparison may be made by evaluating the cumulative energy flow through the foundation wall over the course of the season. Such an analysis is presented in Figure 17, showing the cumulative energy loss expressed in terms of kilowatt-hours/square foot of foundation wall. This value was obtained by integrating the heat flux over time.

By the time the data recording system was turned off in mid-May, the differential between the two sides was 1.24 kilowatt-hours per square foot of foundation wall, for a ratio of 2.97:1. To relate this value to home use, we postulate a single-story, $2200 \mathrm{sq}$. $\mathrm{ft}$ home. It includes some architectural features such as reentrant corners, and thus its 4-ft. deep foundation encompasses a perimeter $200 \mathrm{ft}$. in length. For such a home, the calculated foundation heat flow differential would amount to a savings of $990 \mathrm{~kW}$-hrs over just the 3 months that the living space was heated, or $330 \mathrm{~kW}$-hrs per month. March, April, and May, are not the coldest months of the year, either. Extrapolating to 
an 8-month heating year, we would expect to save over $2640 \mathrm{~kW}$-hrs per year for our postulated home. The savings for a basement foundation, rather than a crawlspace, would approach twice that, nearing $5280 \mathrm{~kW}-\mathrm{hr}$ per year.

\section{Conclusions}

This simple experiment has shown that a remarkable energy savings is available by insulating the outside of foundations with 2-inch thick (R 10) rigid insulation board. The long-term energy loss rate through the insulated crawlspace was consistently less than one-third that through the non-insulated side. This translated to a savings of $1.24 \mathrm{~kW}$-hrs per square foot of crawlspace wall per month — a significant amount for today's large-footprint homes. The savings for a basement foundation would be approximately double that, or $2.5 \mathrm{~kW}$-hrs per foot of wall per month. Savings would be greater in the coldest months of the year.

\section{Recommendations for further study}

The characterization of external foundation insulation will not be complete until its moisture transport properties have been evaluated, especially with respect to internal foundation insulation. It would be quite instructive to add internal foundation insulation to the currently non-insulated crawlspace, along with moisture sensors throughout the system. We could then place specific quantities of water on either side of the foundation wall, and monitor the transport and collection of moisture through both systems over the course of a year.

\section{References}

1. Yost, N., Lstriburek, J., Basement Insulation Systems, www.buildingscience.com, 2003

2. Lstiburek, J., Builder's Guide, Cold Climates, Energy and Environmental Building Association, January, 2001.

3. Kreith, F., Principles of Heat Transfer, $2^{\text {nd }}$ Ed., International Textbook Company, Scranton, PA, 1965. 


\section{Figures}

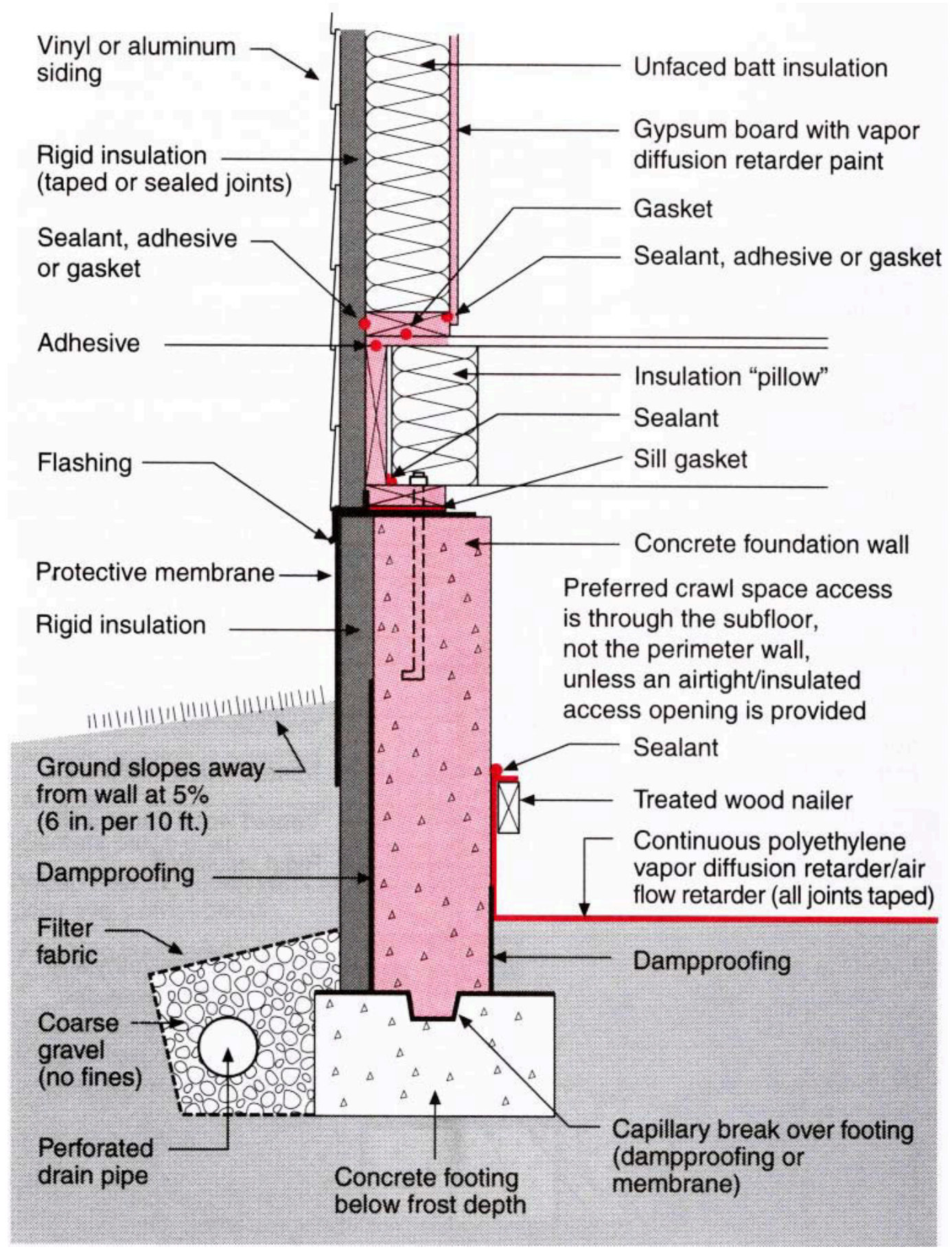

Figure 1. Schematic of EEBA external foundation insulation (Ref. 2) 

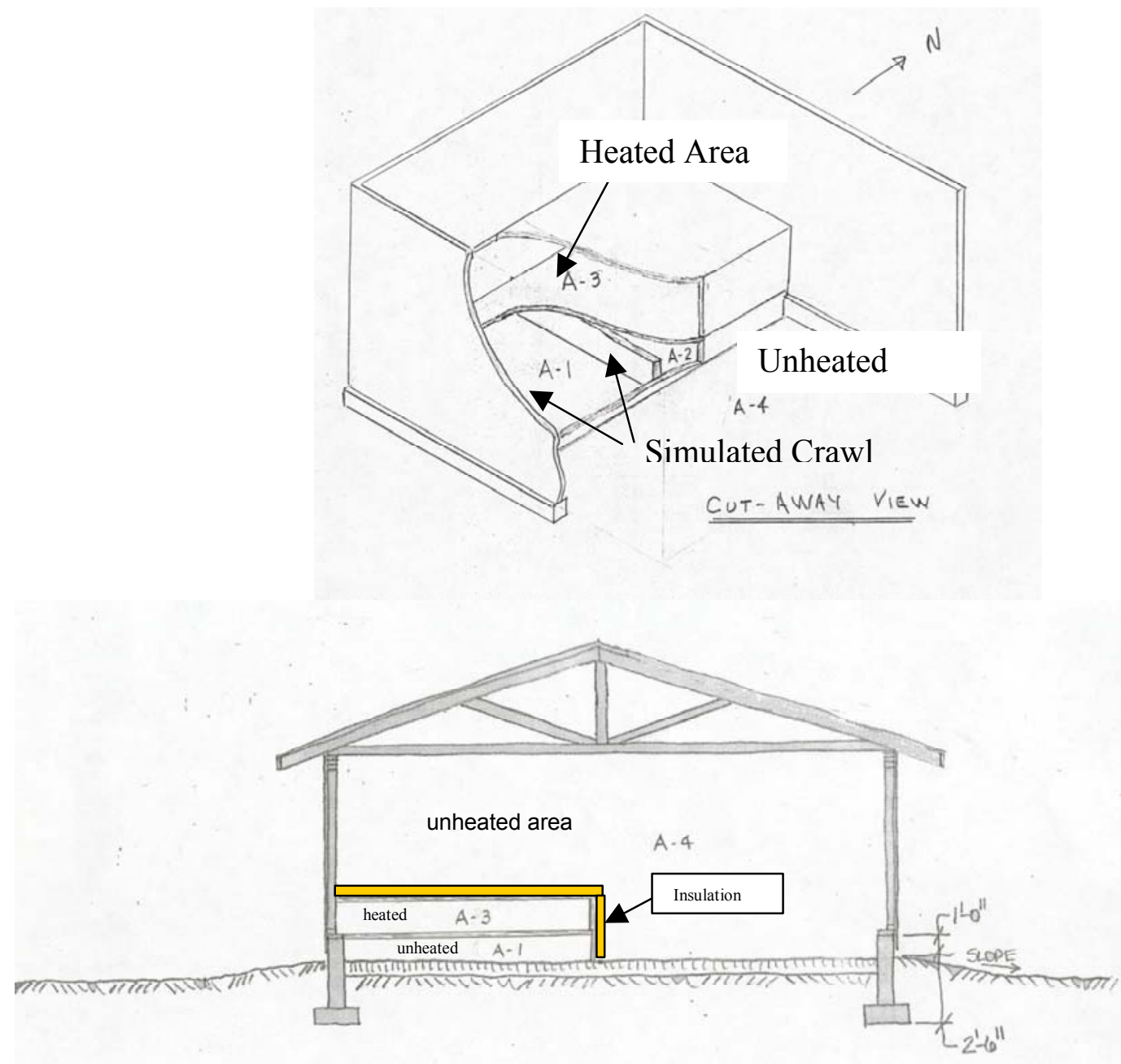

$$
\frac{\text { EAST - WEST Section }}{(\text { South Half) }}
$$

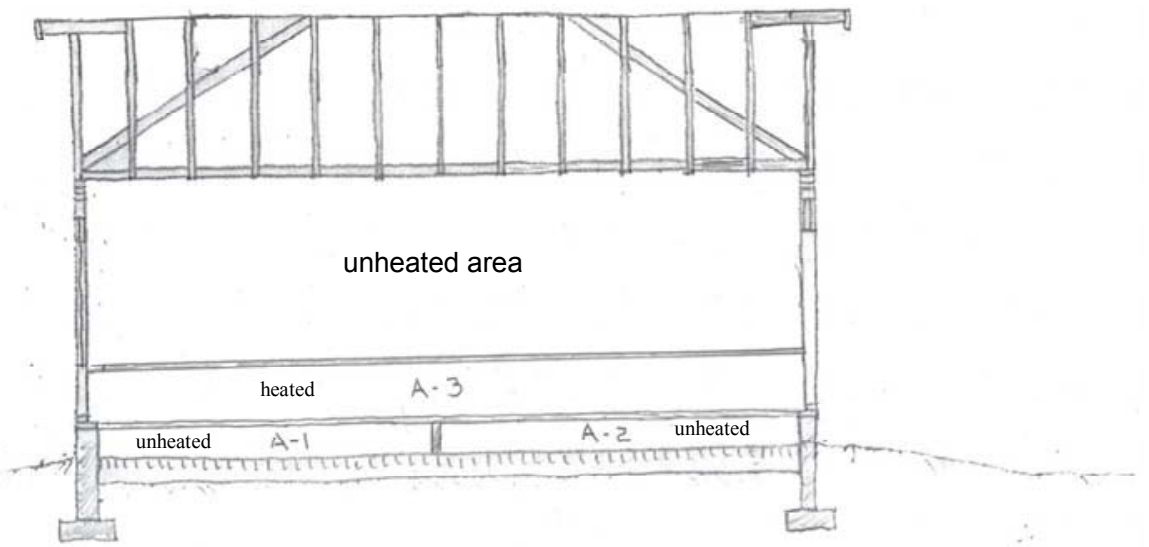

Figure 2. Schematic of test space 


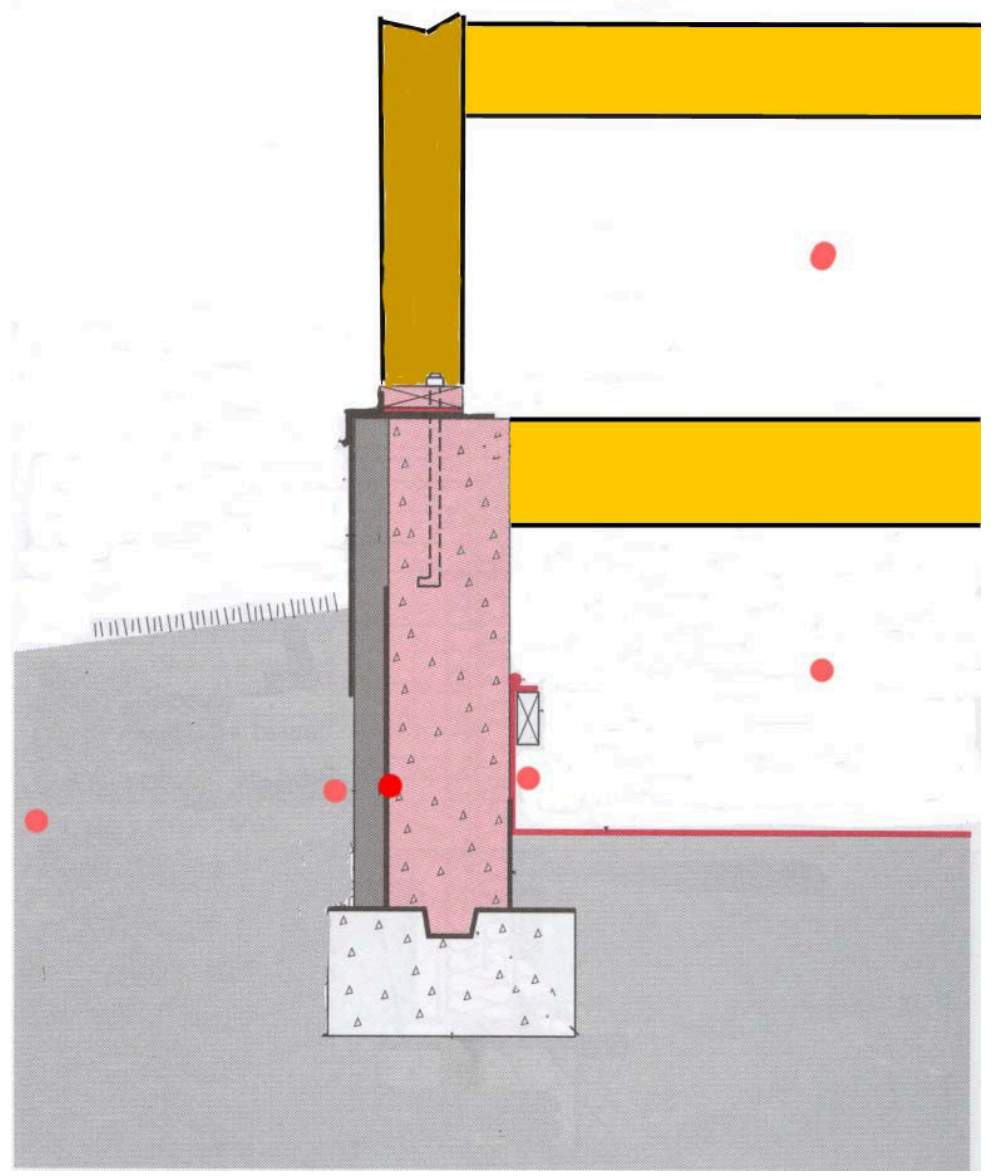

Figure 3. Typical sensor group configuration 


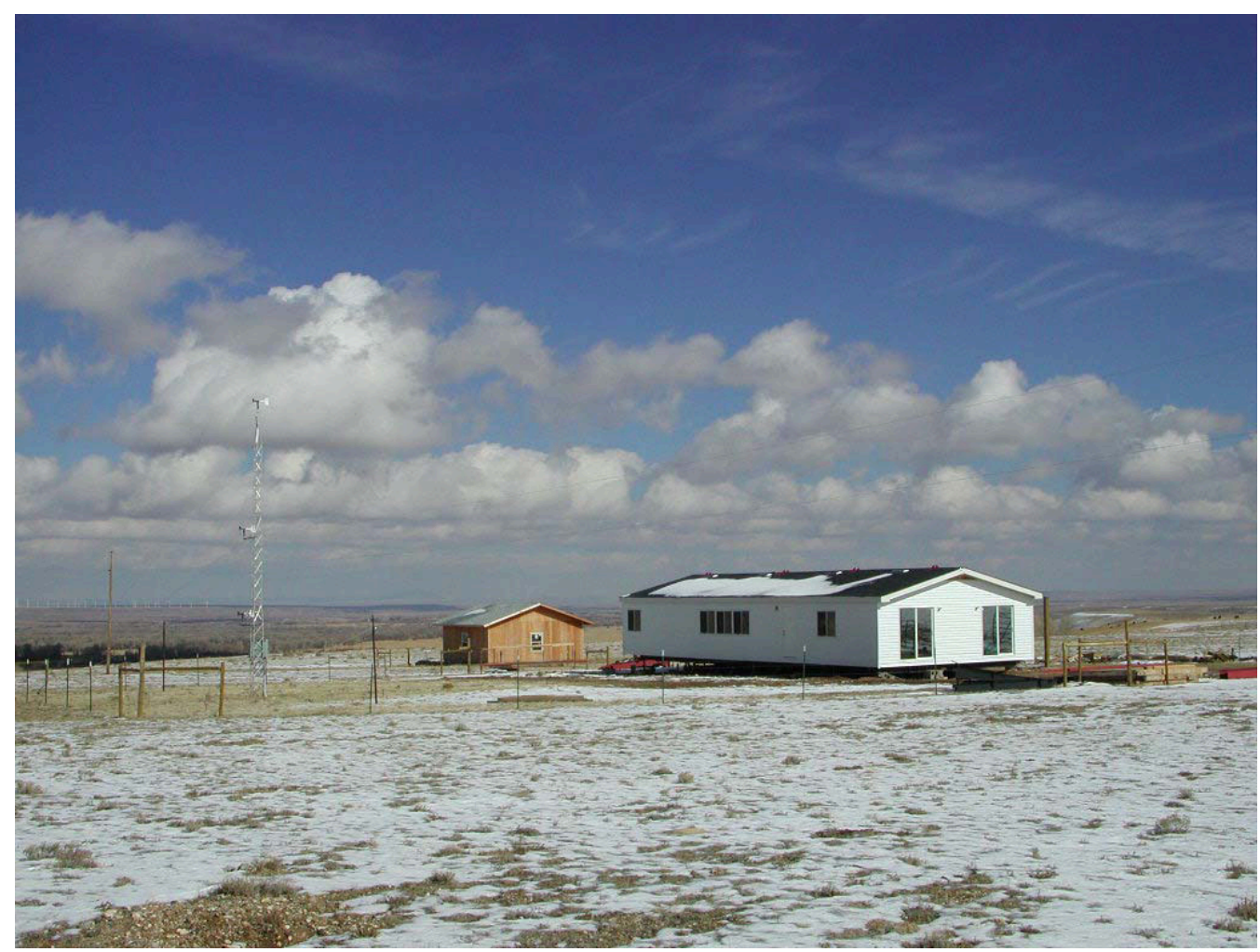

Figure 4. The INEEL Severe Weather Test Site

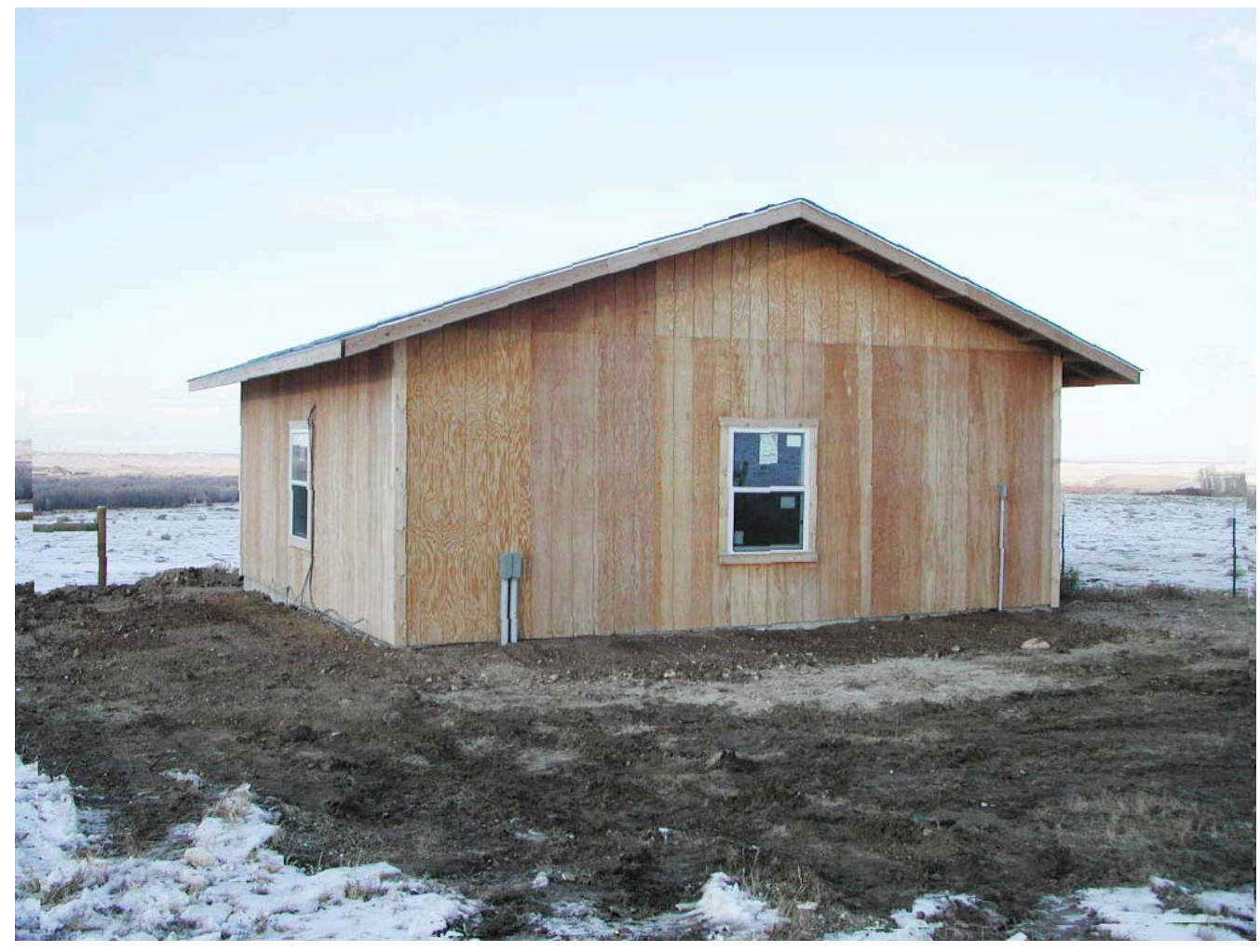

Figure 5. The Simpson Strong-Tie Building. 


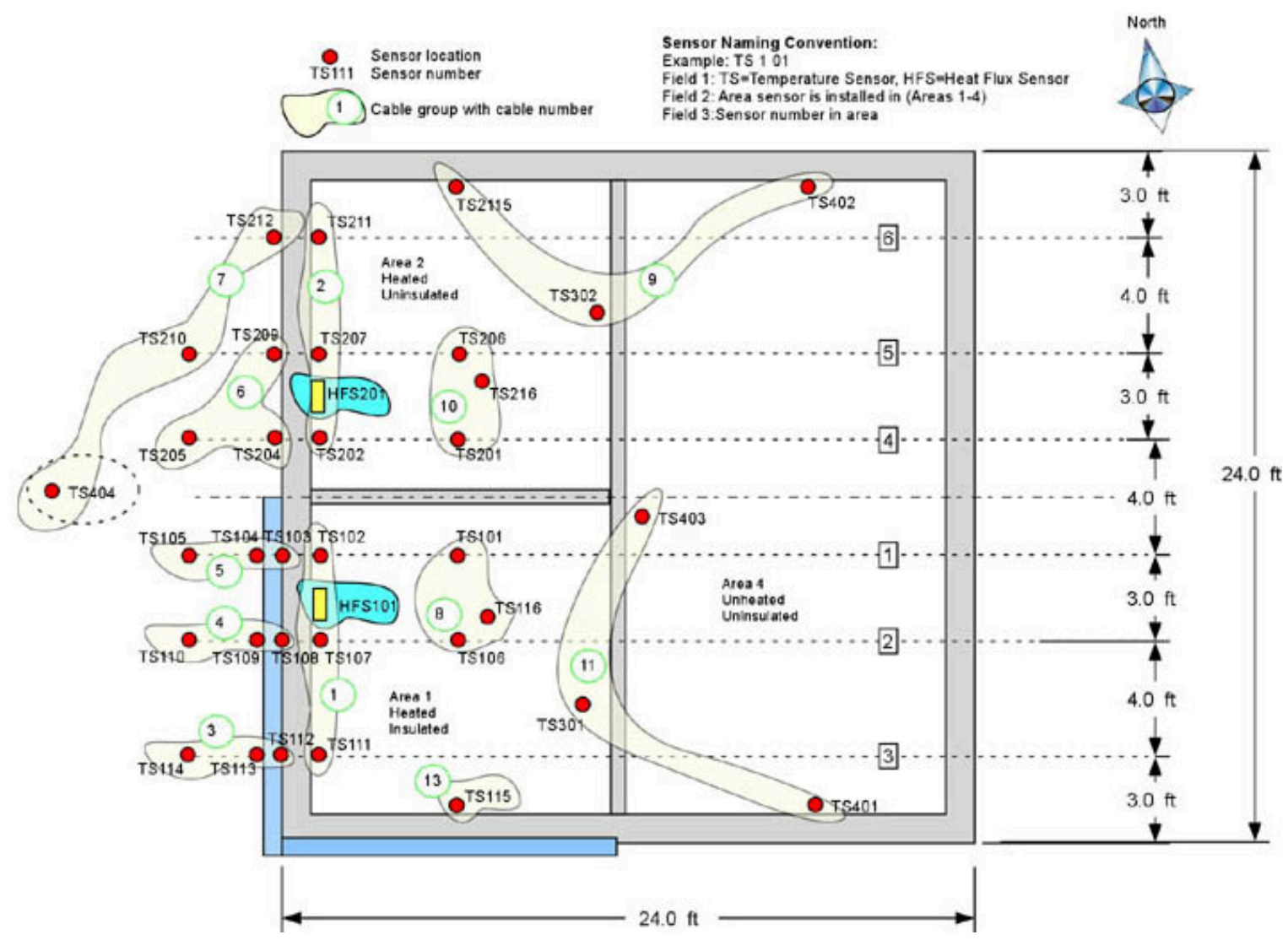

Figure 6. Sensor layout and cabling

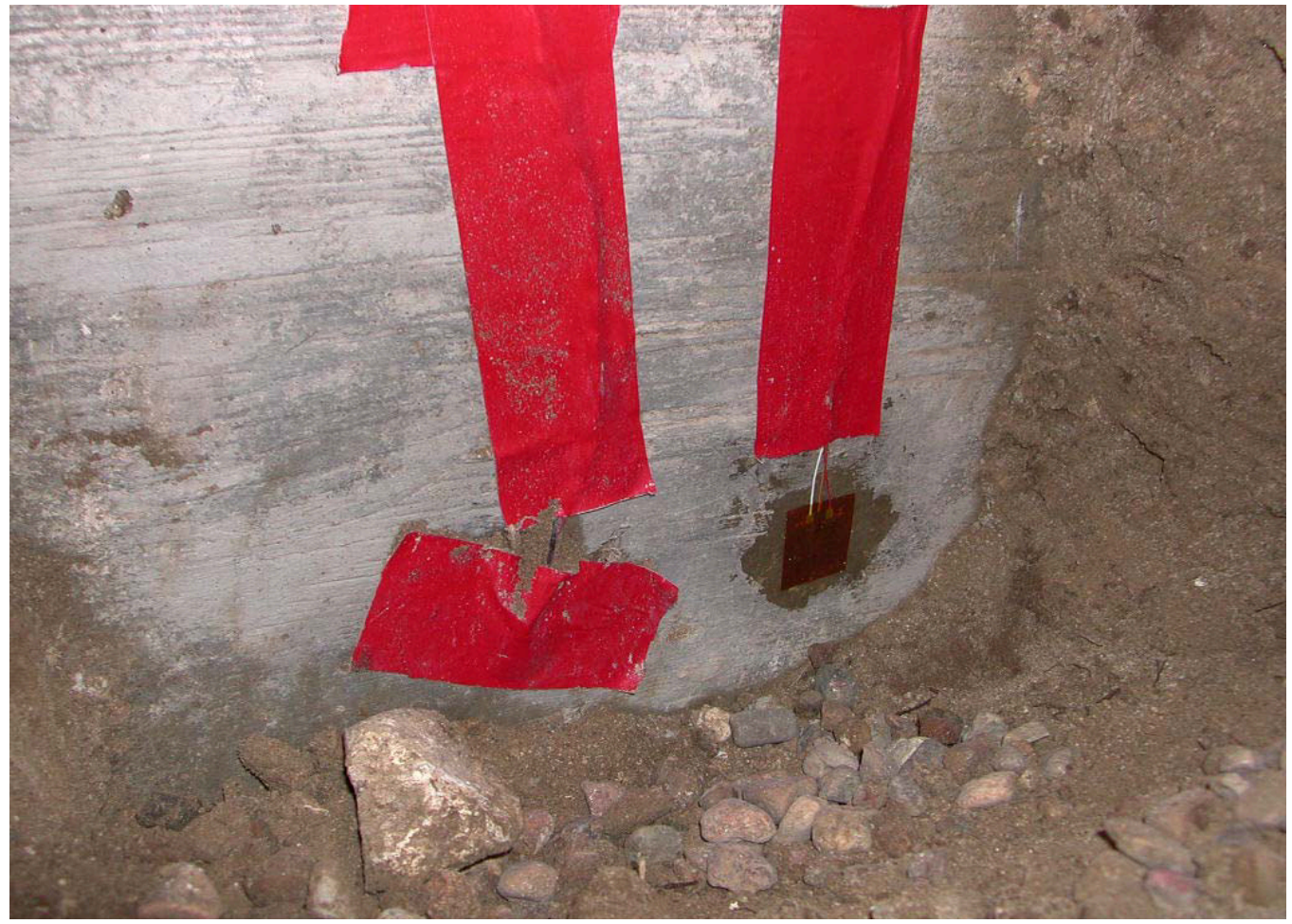

Figure 7. Temperature sensor and heat flux sensor as placed on foundation interior 


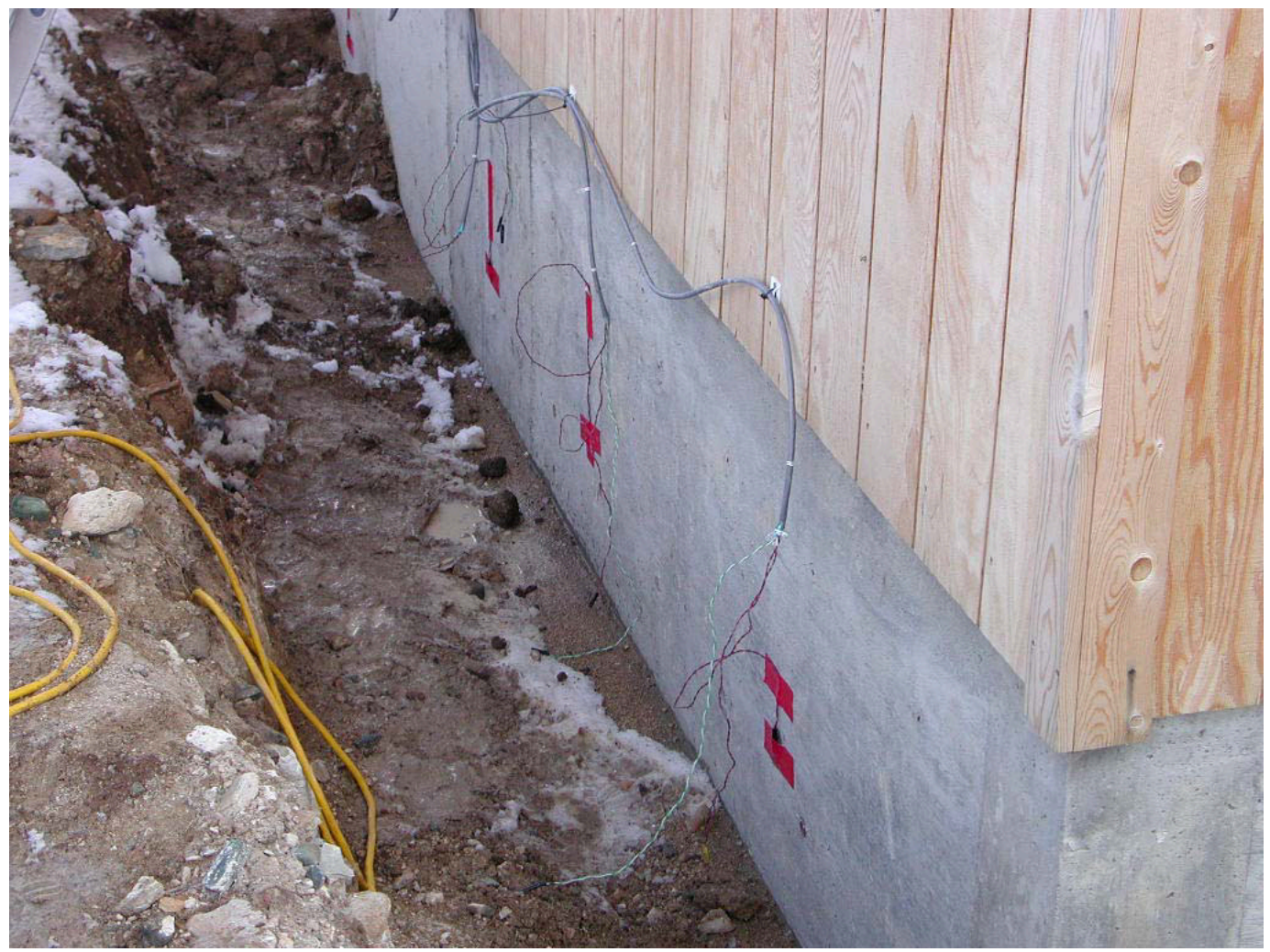

Figure 8. Temperature sensors installed on outside surface of foundation.

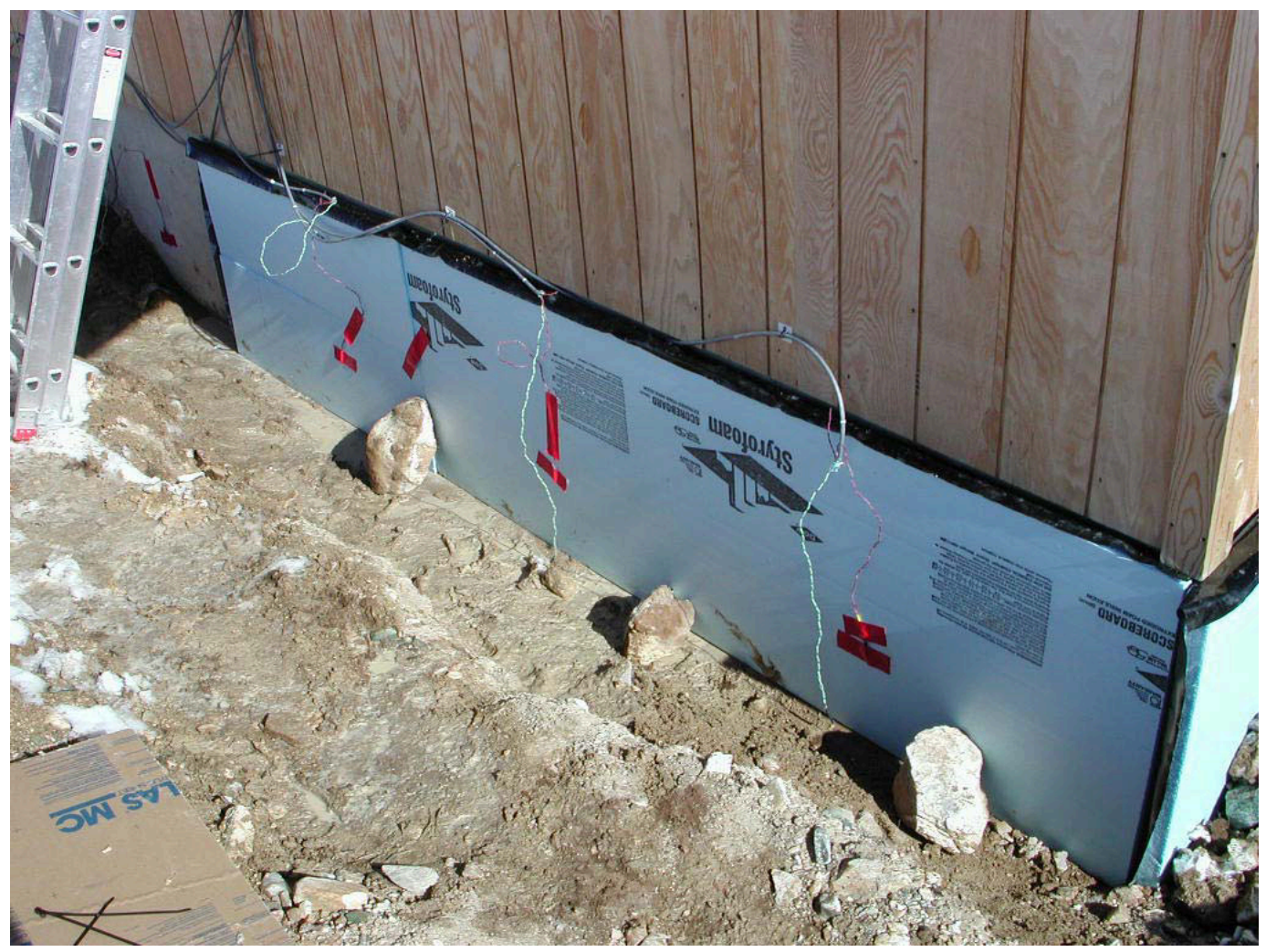

Figure 9. Temperature sensors installed on outside face of insulation. 


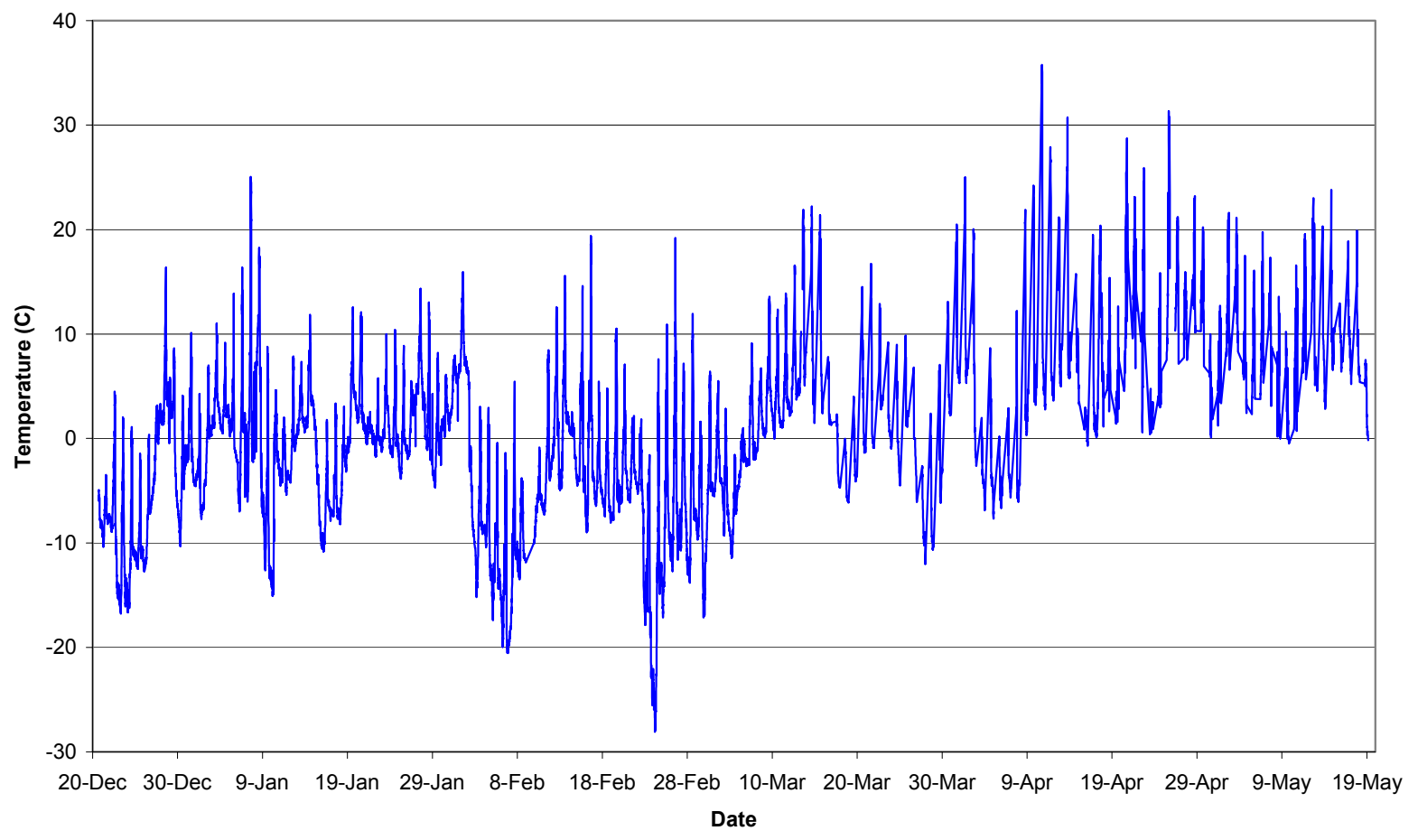

Figure 10. Air temperature history, west wall

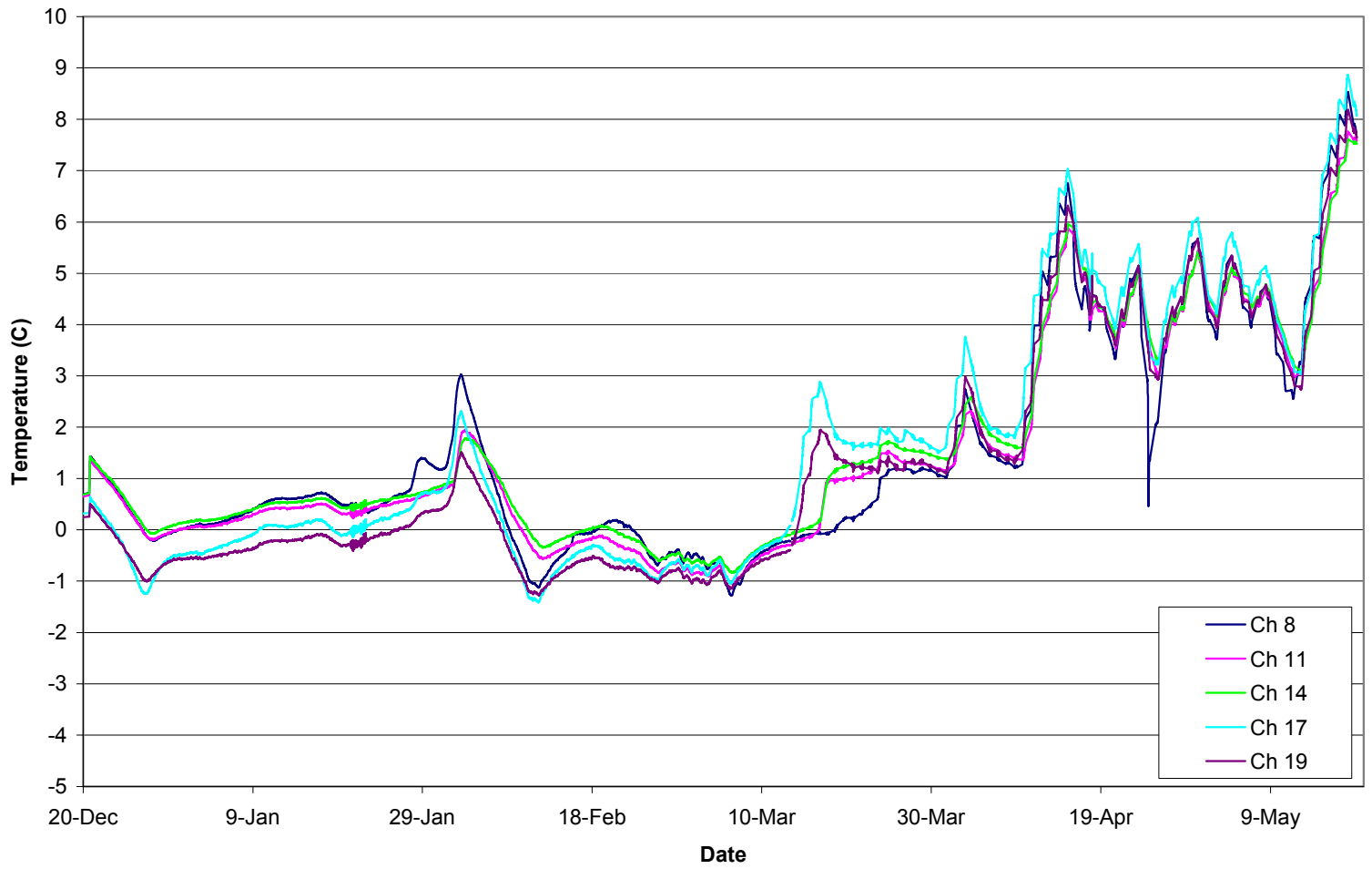

Figure 11. Outside ground temperature history 


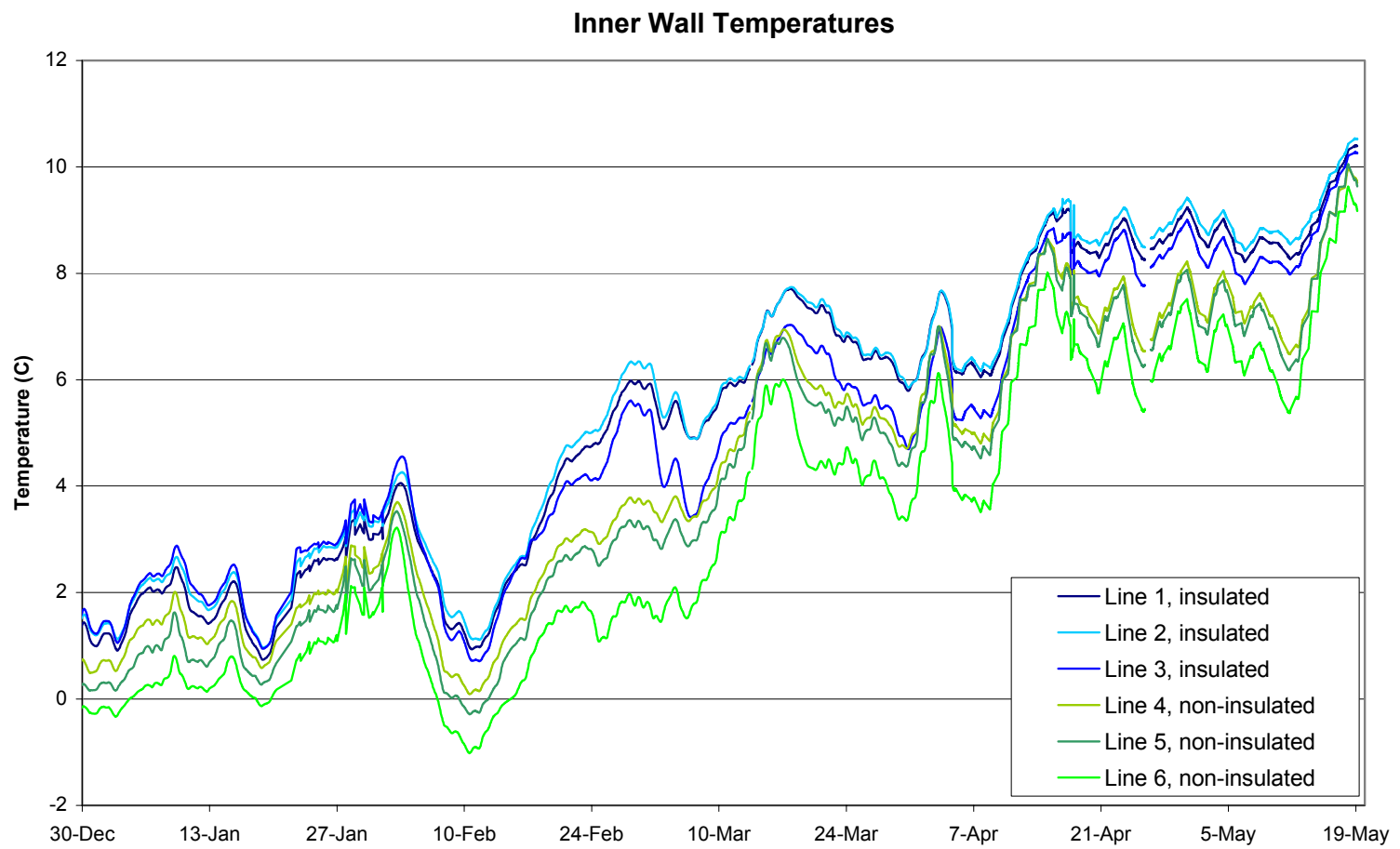

Figure 12. Temperature history of the foundation interior surface

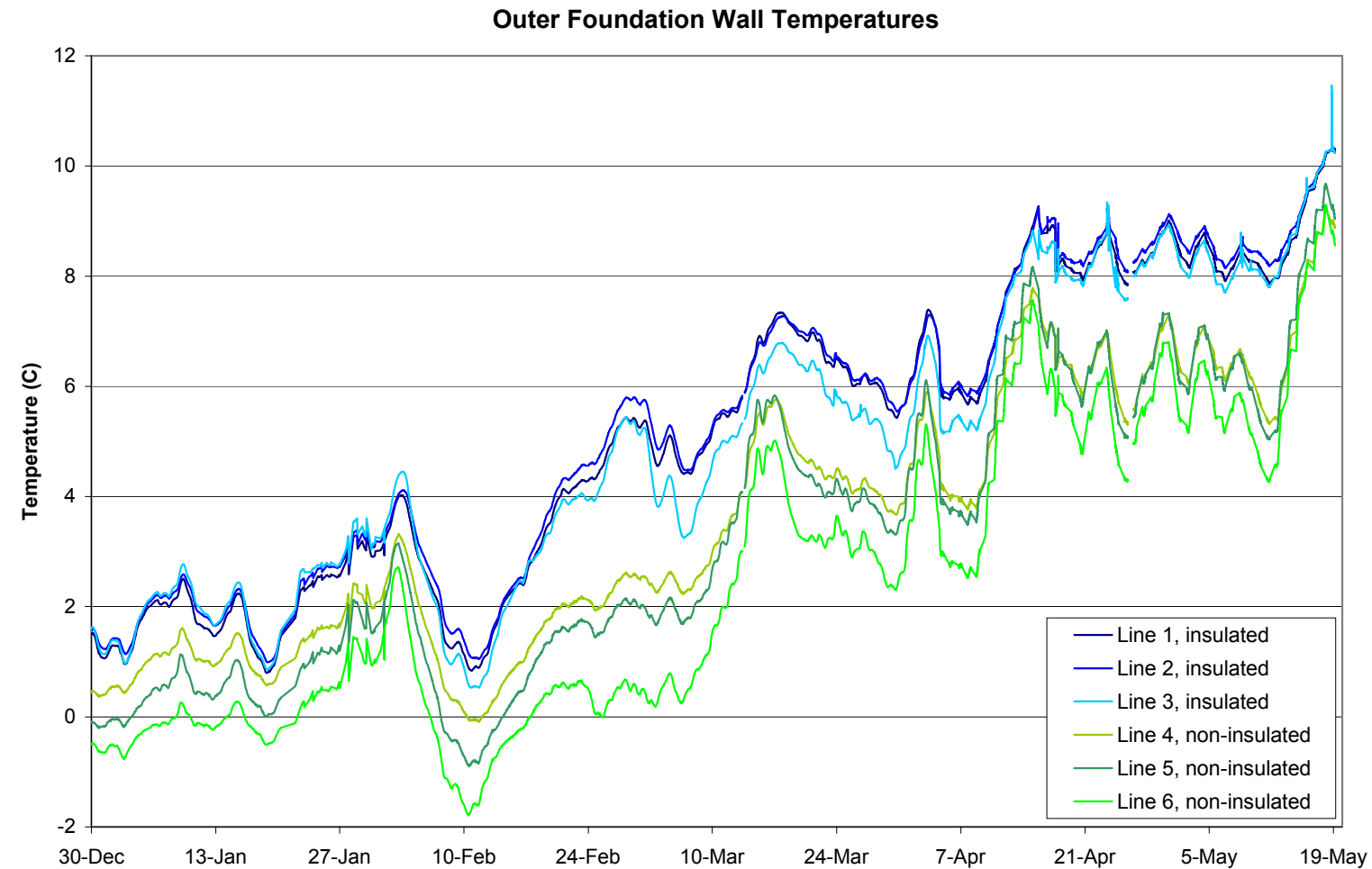

Figure 13. Temperature history of the foundation exterior surface 


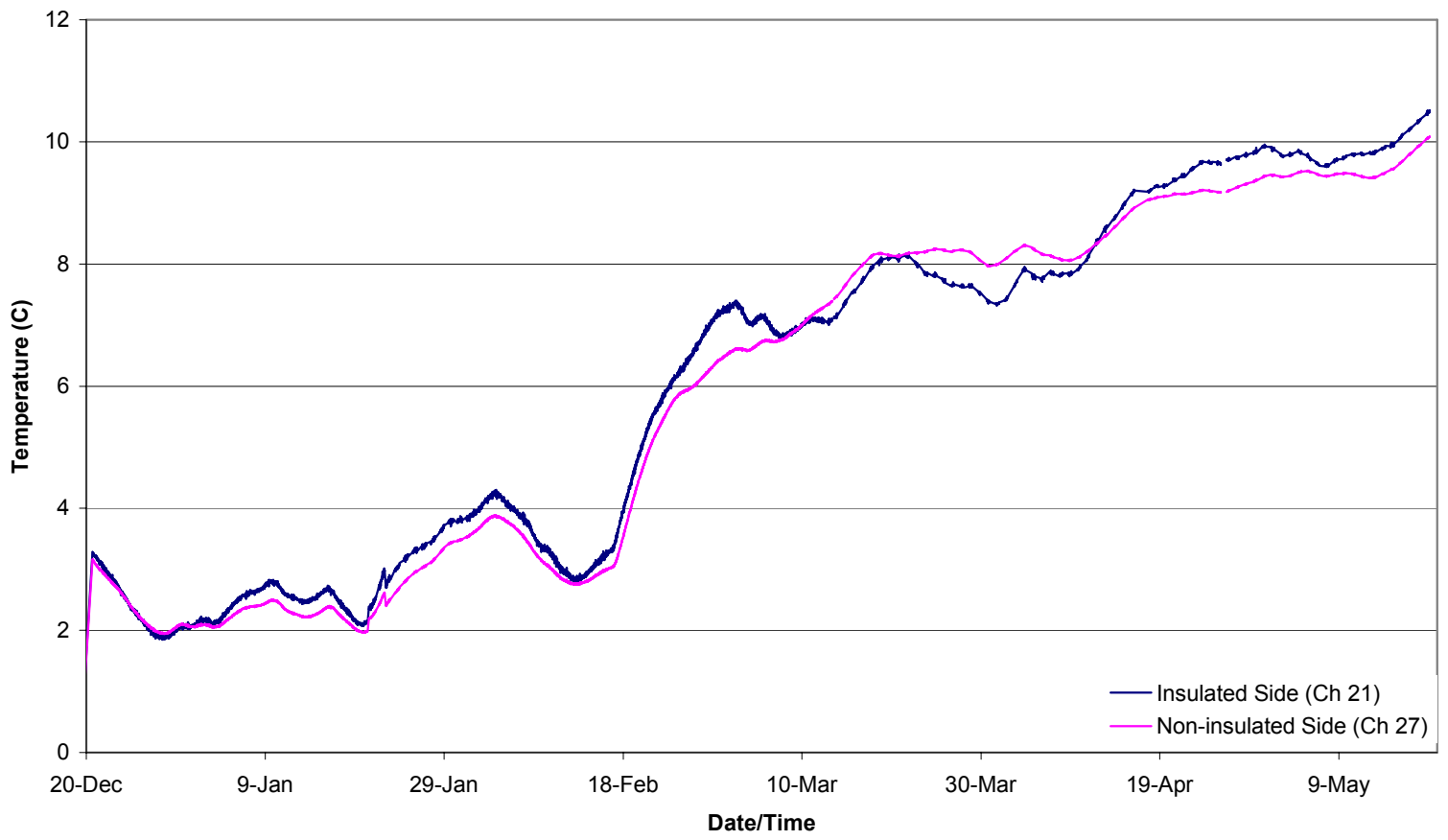

Figure 14. Crawlspace soil temperature history at 18in. depth

Temperature Profiles

24-hr mean, Feb 27-28

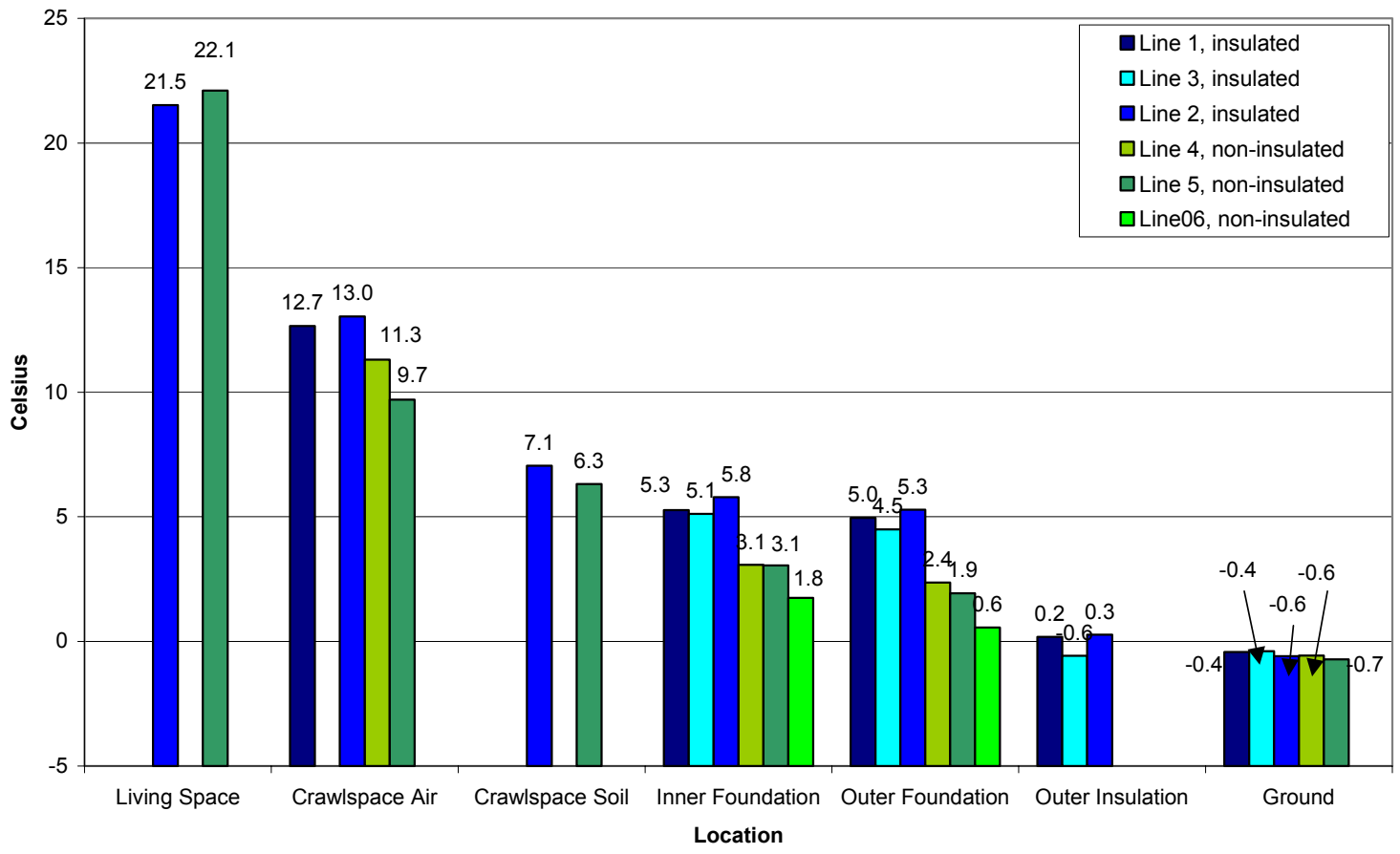

Figure 15. Temperature profile through the system, February 27 


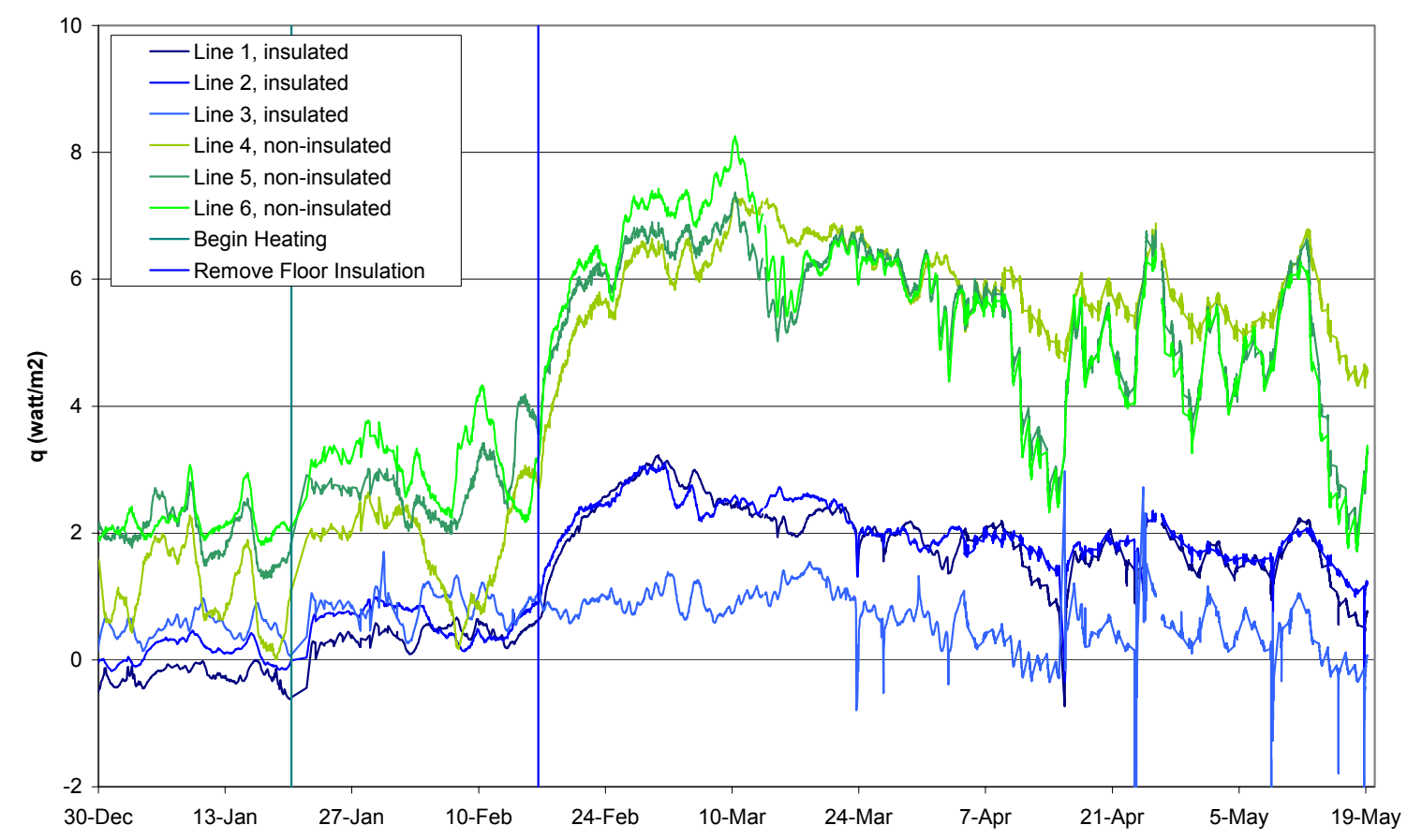

Figure 16. Seasonal heat flux through the foundation wall

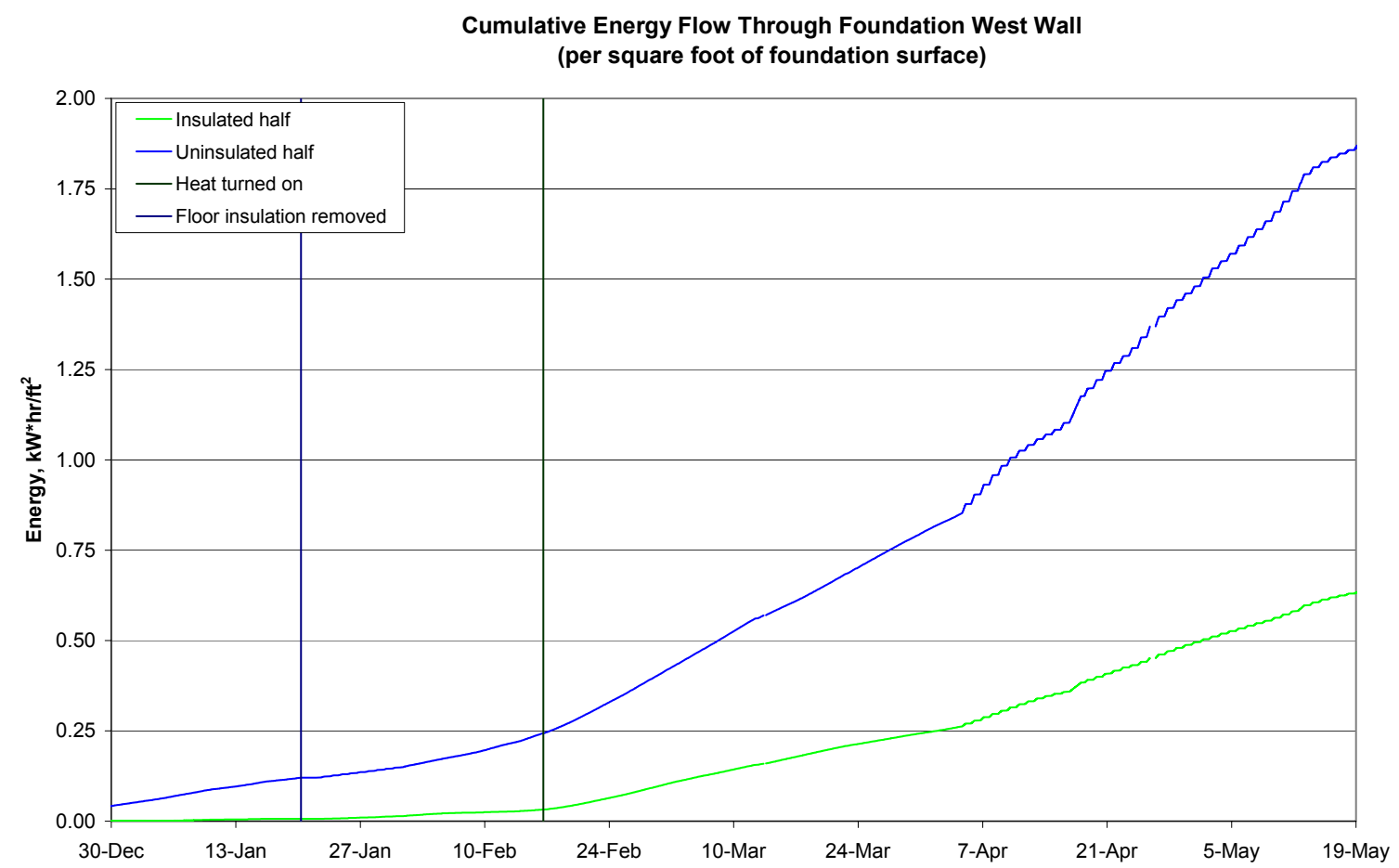

Figure 17. Cumulative energy flow through foundation, per square foot of foundation surface 